\title{
Synthesis and Spectroscopic Study of Some Organotin(IV) Derivatives of N,N'-O- Phenylenebis(Salicylideneimine)
}

\author{
M. David Raju \\ Department of Chemistry, Post Graduate Center \\ P.B.Siddhartha College Of'Arts\& Science, Vijayawada,(A.P) 520010, India \\ Email mdavid20042003@yahoo.com
}

\begin{abstract}
Some di-and triorganotin(IV) derivatives of N,N'-o-phenylenebis(salicylideneimine) were synthesised by the reactions of the corresponding $\mathrm{di}$ and triorganotin(IV) chlorides with the sodium salt of $\mathrm{N}, \mathrm{N}^{\prime}-\mathrm{O}$ phenylenebis(salicylideneimine) in different molar ratios. These derivatives have been characterized by elemental analyses, molecular weights, conductivity measurements and spectral(IR, ${ }^{1} \mathrm{H},{ }^{13} \mathrm{C}$ and ${ }^{119} \mathrm{Sn}$ NMR) studies.
\end{abstract}

\section{INTRODUCTION}

A considerable amount of work has been carried out on organotin(IV) complexes with $\mathrm{S}, \mathrm{N}$ and $\mathrm{O}$ donar ligands /1-3/ particularly, derived from salicylaldehyde and various amines, /4,5/ from our laboratory. o-Hydroxyacetophenone glycine complexes of organotin(IV) have already been reported /6/ exhibiting interesting coordination patterns. Very little attention has been paid to the Schiff base derived from salicylaldehyde and 2-amino-5-chlorobenzophenone, which is an important metabolite precursor for the synthesis of drugs, known as 1,4-benzodiazepines /7/. In continuation of our studies on organotin(IV) derivatives $/ 8$ /, we report here the synthesis and characterization of some new complexes of organotin(IV) with $N, N^{\prime}-0$ - phenylenebis(salicylideneimine).

\section{EXPERIMENTAL}

Due to the highly hygroscopic nature of the metal alkoxides, stringent precautions were taken to exclude moisture throughout the experiments, using glassware with interchangeable joints. All the reactions were carried out under strictly anhydrous conditions and analytical grade chemicals were used for all experiments. The Schiff bases were synthesized by the condensation of salicyldehyde and o-phenylenediamine in 2:1 
molar ratio in benzene as reaction medium. This solution was refluxed for 3-4 $\mathrm{h}$ and then allowed to cool to room temperature. The products so obtained were recrystallised from pet.ether-benzene mixture.

Tin was determined as tin oxide gravimetrically and nitrogen was determined by Kjeldahl's method. Infrared spectra were recorded on a Perkin-Elmer model 377 spectrophotometer in the range $4000-400 \mathrm{~cm}^{-1}$. The ${ }^{1} \mathrm{H}$ NMR spctra were recorded on a jeol FX -90 using tetramethylsilane as an external standard.

\section{Reaction between triphenyltin(IV)chloride and sodium salt of $\mathbf{N}_{\mathbf{1}} \mathbf{N}^{\prime}-0-$ phenylenebis(salicylideneimine) in a $1: 1$ molar ratio:}

$0.07 \mathrm{~g}$ of sodium metal and $15 \mathrm{ml}$ of isopropanol were taken in a round bottom flask (fitted with a watercooled condenser and dryingguard tube) and refluxed for about half an hour till a clear solution of sodium isopropoxide was obtained. After cooling, $1.10 \mathrm{~g}$ (3mmole) of $\mathrm{N}, \mathrm{N}^{\prime}-\mathrm{O}-$ phenylenebis(salicylideneimine) was added and the mixture was refluxed for two hours again. $1.20 \mathrm{~g}$ (3mmole) of triphenyltin choride was added and the mixture was further refluxed for two hours to ensure completion of the reaction. The desired product $(80 \%)$ was isolated by evaporation of the solvent under reduced pressure, after filtering of the precipitated sodium chloride. The product was further purified by recrystallization using a benzene-petroleum ether $\left(40^{\circ}\right.$ $60^{\circ}$ ) mixture.

All other organotin (IV) derivatives of $\mathrm{N}, \mathrm{N}^{\prime}-0$ - phenylenebis(salicylideneimine) were synthesized analogously. The pertinent data for this compound and other derivatives are listed below.

\section{RESULTS}

Compound 1. $\mathrm{C}_{26} \mathrm{H}_{20} \mathrm{~N}_{2} \mathrm{O}_{2} \mathrm{Sn}$

Yield 79\%; Mol.Wt. [F (C)]: 510 (511.16);yellow solid;M.P.103-105c.

Analysis [\%F (C )]:Sn,22.12 (23.22),H,3.20 (3.39);N.5.00 (5.48);O,5.60 (6.26)

IR $\left(\mathrm{cm}^{-1}\right): v C=0,1680 ; v \mathrm{C}=\mathrm{N}, 1605 ; v \mathrm{Sn}-\mathrm{O}, 485$.

PMR (ppm): 8.65 (s,2H,CH=N),7.46-7.65 (m,12H,Ar). ${ }^{119} \mathrm{Sn} \mathrm{NMR} \mathrm{(ppm):}-115.62$

${ }^{13}$ CNMR (ppm): $166.23,160.65,154.34,142.46,133.42,132.48,127.63,119.42,119.12,118.86,116.43$; MS (El, 70Ev): $\mathrm{m} / \mathrm{z} 342\left(\mathrm{M}^{+}, 26\right), 314,298,282,208,192,77$.

Compound $2 \mathrm{C}_{24} \mathrm{H}_{24} \mathrm{~N}_{2} \mathrm{O}_{2} \mathrm{Sn}$

Yield 89\%; Mol.Wt. [F (C)]: 490.0 (491.17);yellow solid;M.P.104-106 ${ }^{\circ}$ c.

Analysis [\%F (C )]:Sn,22.12 (24.17),H,4.10 (4.93);N.5.00 (5.70);O,5.60 (6.51)

IR $\left(\mathrm{cm}^{-1}\right): v C=0,1685 ; v \mathrm{C}=\mathrm{N}, 1600 ; v$ Sn-O, 480 .

PMR (ppm): 8.70 (s,2H,CH=N),7.50-7.69 (m,12H,Ar). ${ }^{119}$ Sn NMR (ppm): -84.82

${ }^{13}$ CNMR (ppm):166.35,161.00,154.45,142.50,133.50,133.00,127.70,119.50,119.17,117.90,116.52; MS (El; $70 \mathrm{Ev}): \mathrm{m} / \mathrm{z} 342\left(\mathrm{M}^{+}, 26\right), 316,297,284,209,193,79$. 


\section{Compound $3 \mathrm{C}_{24} \mathrm{H}_{24} \mathrm{Cl}_{2} \mathrm{~N}_{2} \mathrm{O}_{2} \mathrm{Sn}$}

Yield 89\%; Mol.Wt. [F (C)]: 490. (562.08);yellow solid;M.P.104-106 ${ }^{\circ} \mathrm{c}$.

Analysis [\%F (C)]:Sn,22.12 (21.12),H,4.10 (4.30);N.5.00 (4.98);O,5.60 (5.69)Cl 12.60 (12.61),C50.28 (51.28).

IR $\left(\mathrm{cm}^{-1}\right): v C=0,1685 ; v \mathrm{C}=\mathrm{N}, 1600 ; v \mathrm{Sn}-\mathrm{O}, 480$.

PMR (ppm): 8.70 (s,2H,CH=N),7.50-7.69 (m,12H,Ar)., ${ }^{119}$ Sn NMR (ppm): -1 18.6

${ }^{13}$ CNMR (ppm): $166.35,161.00,154.45,142.50,133.50,133.00,127.70,119.50,119.17,115.90,116.52$; MS (El, 70Ev): m/z $342\left(\mathrm{M}^{+}, 26\right), 316,297,284,209,193,79$.

\section{Compound $4 \mathrm{C}_{54} \mathrm{H}_{66} \mathrm{~N}_{4} \mathrm{O}_{4} \mathrm{Sn}$}

Yield 89\%; Mol.Wt. [F (C)]: 690.0 (967.86);yellow solid;M.P.109-110م.

Analysis [\%F (C )]:Sn, 12.12 (12.27),H,3.10 (7.08);N.5.00 (5.78);O,6.50 (6.60) C870.68

IR $\left(\mathrm{cm}^{-1}\right): v C=0,1687 ; v \mathrm{C}=\mathrm{N}, 1608 ; v \mathrm{Sn}-\mathrm{O}, 480$.

PMR (ppm): 8.70 (s,2H,CH=N), 7.50-7.69 (m,12H,Ar). ${ }^{119} \mathrm{Sn} \mathrm{NMR} \mathrm{(ppm):}-420.20$

${ }^{13}$ CNMR (ppm): 166.35,161.00,154.45,142.50,133.50,133.00,127.70,119.50,119.17,114.90,116.52; MS (El, $70 \mathrm{Ev}): \mathrm{m} / \mathrm{z} 342\left(\mathrm{M}^{+}, 26\right), 314,298,284,209,193,79$.

Compound $5 \mathrm{C}_{21} \mathrm{H}_{18} \mathrm{ClN}_{2} \mathrm{O}_{2} \mathrm{Sn}$

Yield 89\%; Mol.Wt. [F (C)]: 480.0 (484.54);yellow solid;M.P.110-114 ${ }^{\circ} \mathrm{c}$.

Analysis [\%F (C )]:Sn,22.12 (24.50),H,4.10 (4.93);N.5.00 (5.70);O,5.60 (6.51) C870.68

IR $\left(\mathrm{cm}^{-1}\right): v C=0,1685 ; v \mathrm{C}=\mathrm{N}, 1600 ; v \mathrm{Sn}-\mathrm{O}, 480$.

PMR (ppm): 8.70 (s,2H,CH=N), 7.50-7.69 (m,12H,Ar). ${ }^{119} \mathrm{Sn}$ NMR (ppm): -126.52

${ }^{13}$ CNMR (ppm): 166.35,161.00,154.45,142.50,133.50,133.00,127.70,119.50,119.17,113.90,116.52; MS (El, 70Ev): $\mathrm{m} / \mathrm{z} 342\left(\mathrm{M}^{+}, 26\right), 315,299,284,209,191,79$.

\section{Compound $6 \mathrm{C}_{48} \mathrm{H}_{55} \mathrm{~N}_{4} \mathrm{O}_{4} \mathrm{Sn}$}

Yield 89\%; Mol.Wt. [F (C)]: 869.0 (870.68);yellow solid;M.P.104-106 ${ }^{\circ} \mathrm{c}$.

Analysis [\%F (C)]:Sn, 12.12 (13.63),H,6.10 (6.37);N.6.40 (6.43);O,7.60 (7.35)C,66.20 (66.21)

IR $\left(\mathrm{cm}^{-1}\right): v C=O, 1685 ; v \mathrm{C}=\mathrm{N}, 1600 ; v \mathrm{Sn}-\mathrm{O}, 480$.

PMR (ppm): 8.70 (s,2H,CH=N), 7.50-7.69 (m,12H,Ar). ${ }^{119}$ Sn NMR (ppm): -420.32

${ }^{13}$ CNMR (ppm): $166.35,161.00,154.45,142.50,133.50,133.00,127.70,119.50,119.17,115.90,116.52$; MS (El, $70 \mathrm{Ev}): \mathrm{m} / \mathrm{z} 342\left(\mathrm{M}^{+}, 26\right), 316,299,281,209,192,79$.

\section{RESULTS}

Triorganotin(IV) and diorganotin(IV) derivatives of N,N'-o-phenylenebis(salisilidenei mine) have been synthesized by the reaction of corresponding triorganotin(IV) and diorganotin(IV) chlorides with the ligand (prepared in situ by the reaction of sodium isopropoxide with the ligand) in 1:1 and1:2 molar ratios, respectively. 
<smiles>[R5][SbH2]Cl</smiles><smiles>[R3][Sb]([R3])(Oc1ccccc1/C=N\c1ccccc1O)N1Cc2ccccc2O1</smiles>

(where $\mathrm{R}=\mathrm{Ph}$, Compd.1; $\mathrm{R}=\mathrm{n}-\mathrm{Bu}$, Compd.2)

$\mathrm{R}_{2} \mathrm{SnCl}_{2}+\mathrm{nNa}+\mathrm{n}$<smiles>C=Cc1ccccc1O</smiles><smiles>Nc1ccccc1/N=C/c1ccccc1O</smiles><smiles></smiles>

( where $\mathrm{R}=\mathrm{n}-\mathrm{Bu}, \mathrm{n}=1$. Compd.3; $\mathrm{R}=\mathrm{n}-\mathrm{Bu}, \mathrm{n}=2$, Compd.4; $\mathrm{R}=\mathrm{Me}, \mathrm{n}=1$, Compd. $5 ; \mathrm{R}=\mathrm{Me}, \mathrm{n}=2$, Compd.6)

All these newly synthesized compounds are yellow crystalline solids, soluble in common organic and coordinating solvents. Molar conductance values reveal the non-electrolytic nature of the complexes indicating that the ligand is covalently bonded to tin. Molecular weight determination in $\mathrm{CHCl}_{3}$ solution shows their monomeric nature.

\section{IR Spectral Data}

The infrared spectra of these organotin(IV)complexes have been recorded in the form of $\mathrm{KBr}$ pellets in the range $4000-400 \mathrm{~cm}^{-1}$. Tentative assignments have been made on the basis of earlier publications $/ 4,5 /$.

The spectrum of the ligand shows bands in the regions $3260-3380,1620 \mathrm{~cm}^{-1}$, which have been assigned to $v(\mathrm{OH}), v(\mathrm{C}=\mathrm{N})$ respectively $/ 9 /$. The disappearance of the $3260 \mathrm{~cm}^{-1}$ band indicates the deprotonation of one of the $\mathrm{O}-\mathrm{H}$ groups and consequent coordination of phenolic oxygen atom to tin metal, which is further substantiated by the appearance of bands in the region $570-440 \mathrm{~cm}^{-1}$, that may be due to $\mathrm{Sn}-\mathrm{C}$ and Sn-O stretching vibrations $/ 10,11 /$. The band at $3380 \mathrm{~cm}^{-1}$ is unaffected, indicating non involvement of the second $\mathrm{O}-\mathrm{H}$ bond in the coordination. The band present at $1615 \mathrm{~cm}^{-1}$, due to $v \mathrm{C}=\mathrm{N}$ in the ligand, is found to be shifted by about $20-25 \mathrm{~cm}^{-1}$ to a lower wave number in the complexes, suggesting coordination of the two azomethine nitrogens to the central metal atom $/ 13 /$. 


\section{NMR Spectral Data :}

The PMR spectra of ligand is characterised by the appearance of a signal at $12.40 \mathrm{ppm}$ for two phenolic$\mathrm{OH}$ groups, at $10.60 \mathrm{ppm}$ for azomethine group and a multiplet at $6.84-7.86 \mathrm{ppm}$ attributable to protons of the phenyl moiety. The resonance at $12.40 \mathrm{ppm}$ is present in the spectra of the complexes, integration of protons along with the appearance of Sn-O stretching band in IR and Sn NMR suggesting the selective deprotonation of one of the phenolic-OH and its subsequent involvement in coordination. The coordination through azomethine nitrogen is supported by the upfield shift of the free ligand signal at $10.60 \mathrm{ppm}$ to 11.60 ppm in the complexes $/ 14 /$. The resonance due to the phenyl moiety remains unaffected. The PMR spectra of complexes exhibit phenylene proton resonances overlapping with the phenylene proton resonances of the ligand to give a complex pattern at $6.76-8.25 \mathrm{ppm}$. The resonances due to the butyl protons are observed in the region $0.60-1.86 \mathrm{ppm}$, with a well defined triplet at $0.85 \mathrm{ppm}(\mathrm{J}=8 \mathrm{~Hz})$, which is due to methyl protons of the butyl group.

The methyl protons of the dimethyltin(IV) derivatives appear as a sharp singlet at $0.44 \mathrm{ppm}$. A particular advantage of methyl tin derivatives is the ease with which proton spin - spin coupling constant can be determined. The coupling constant provides valuable information about the hybridisation state of tin $/ 15,16 /$. For the four-coordinate dimethyl tin (IV) compounds, these have been found to be $72 \mathrm{~Hz}$, which is in the range of values observed for six-coordinate dimethyltin (IV) compounds, indicating that the ligand behaves as bidendate moiety.

The ${ }^{119} \mathrm{Sn}$ chemical shifts of all the derivatives have been observed in the range of -86.85 to $-433.27 \mathrm{ppm}$. These ${ }^{119} \mathrm{Sn}$ NMR chemical shifts of triphenyltin (IV) and mixed chlorodimethyltin (IV)derivatives contain six-coordinate tin.

Thus, based on the above spectral studies, five-coordinate (a) and six-coordinate (b) structures may be tentatively proposed for triorganotin(IV) and diorganotin(IV) derivatives of the ligand, respectively.<smiles></smiles>

(a)

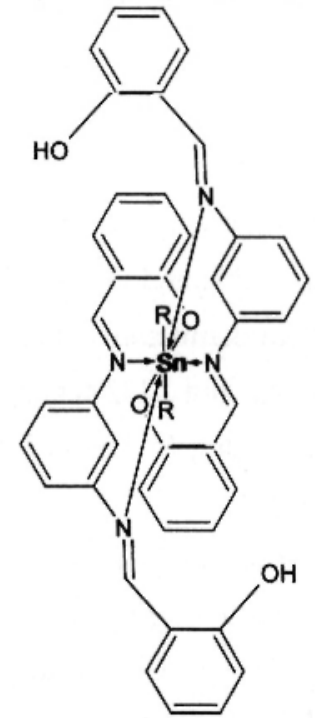

(b)

$(\mathrm{R}=\mathrm{Ph}, \mathrm{Bu})$

$(\mathrm{R}=\mathrm{Me}, \mathrm{Bu})$ 


\section{ACKNOWLEDGEMENT}

I am very grateful to Prof. M. S. Singh, Department of Chemistry, Banarus Hindu University, Varanasi, India for making use of his laboratory and his guidelines. I am thankful to Prof. K. Saraswathi, Head Department of Chemistry, P.G Center, PBS College, Vijayawada, India for the useful discussions. I am very grateful to the SAGTE, Vijayawada, for constant encouragement.

\section{REFERENCES}

1. R.C. Mehrotra, G. Srivastava and B.S. Saraswat, Rev. Silicon, Germanium, Tin and Lead Comp., 6, 171 (1982).

2. M.S. Singh, R.J. Rao and A. Samuel Nalt. Acad Sci, Lett., 19, 114 (1996).

3. P. Dixit and J.P. Tandon, Synth. React. Inorg. Met.-Org. Chem., 18, 439 (1988).

4. R.J. Rao and H.B. Wankhade, Synth. React. Inorg. Met.-Org. Chem., 25, 1049 (1995).

5. R.J. Rao and H.B. Wankhade, Main Group Met. Chem., 19, 4 (1996).

6. H.P.S. Chauhan, A. Bhargava and R.J. Rao, Ind. J. Chem., 32A, 157 (1993).

7. D.J. Greenblat and Shalder, Benzodiazepines in Clinical Practice, North Holland Pub. Co. Amsterdan, 18 (1974).

9. K. Nakamoto, Infrared Spectra of Inorganic and Coordination Compounds, Wiley, New York, (1970).

10. T.N. Srivastava, A.K.S. Chauhan and M. Agrawal, J. Inorg. Nucl. Chem., 41, 986 (1979).

11. R.K. Sharma, R.V. Singh and J.P. Tandon, J. Inorg. Nucl. Chem., 43, 410 (1981).

12. B.K. Tejankar, R.J. Rao and H.P.S. Chauhan, Synth. React. Inrog. Met. -Org. Chem., 21, 1179 (1991)

13. I.U. Khan, S.K. Srivastava and S.C. Srivastava Ind J.Chem., 26A, 238 (1987).

14. N.S. Biradar, G.V. Karajagi, V.L. Roddabasanagoudar and T.M. Aminabhavi, Ind. J. Chem., 24A, 620 (1985).

15. J.R. Holmes and H.D. Kalsz, J. Am. Chem. Soc., 83, 3903 (1961).

16. M.L. Maddox, N. Flitcroff and H.D. Kaesz, J. Organomet. Chem., 4, 50 (1965).

17. K.L. Richie and G. Eng, Inorg, Chim, Acta, 31, L417 (1978).

18. Y. Kawakami and T. Sasaki, Chem. Lett., 1977, 279..

19. S.W. Ng and J.J. Zuckerman, J. Organomet. Chem., 249, 81 (1983).

20. A.K. Gupta, S. Sharma, H.P.S. Chauhan and R.J. Rao, Synth. React. Inorg Met. Org. Chem., 21497 (1991).

21. P.J. Smith and T.P. Tupciauskar, Ann Rep NMR Spectr., 8, 305 (1978).

22. J. Otero, J. Organomet. Chem., 221, 57 (1981).

23. N.A. Denies, K.B. Dillon, R.K. Harries, G.F. Hewitson and L. Tomes, Polyhedron, 13(1), 19 (1994).

24. F. Huber, M. Vornefeld, G. Rui si and R. Barbieri Appl. Organomet. Chem., 7(4), 243 (1993). 